\title{
LA COLABORACION EFICAZ COMO ESTRATEGIA POLÍTICA PROCESAL CONTRA EL CRIMEN EN EL PERÚ
}

\author{
Willian F. Quiroz Salazar*
}

\section{Resumen}

La colaboración eficaz en nuestro país consiste en aportar información válida de un evento delictivo donde el informante haya intervenido como autor, coautor, partícipe del ilícito.

El artículo $472^{\circ}$ del Código Procesal Penal del año 2004 exige que el informante haya declarado voluntariamente sus actividades delictivas, buscando cumplir una doble función, por un lado, la de exigir como requisito que el futuro informante abandone sus actividades ilícitas y por otro, la de rol de prevención general. Finalmente, la colaboración eficaz debe ser vista como una estrategia procesal para enfrentar a la impunidad delictiva y para el descubrimiento de las organizaciones criminales.

Palabras clave: Colaboración eficaz, crimen organizado, informante.

\begin{abstract}
The effective collaboration in our country consists in sharing relevant information of a criminal event where the informant has taken part like author, coauthor, contributor on the felony.

The $472^{\circ}$ article of the Criminal Procedural Code of 2004 demands that the informant has voluntarily declared his criminal activities, looking for to accomplish double attribution, on one hand, to demand as a requirement that the future informant leaves his illicit activities, and on the other hand, the one of general prevention.

Finally, the effective collaboration must be seen like a procedural strategy to face criminal impunity and for the discovery of the criminal organizations.
\end{abstract}

Keywords: Effective collaboration, criminal organizations, informant.

\section{Sumario}

1. Introducción. 2. La colaboración eficaz en el Perú: análisis crítico. 3. Propuestas.

\footnotetext{
* Vocal Provisional de la Corte Superior de Justicia de Lima Norte. Docente universitario y profesor de la Academia de la Magistratura.
} 


\section{INTRODUCCIÓN}

En primer lugar, antes de ir al fondo de lo que pretende este artículo, es pertinente aproximarnos a la estructura conceptual de lo que es colaboración eficaz, derecho penal premial, y crimen organizado, a efecto de tener mayores elementos de estudio que nos permita al final realizar propuestas concretas y reales.

La colaboración eficaz, según la política adoptada por nuestro país, es aportar información válida de un evento delictivo donde el informante haya intervenido como autor, coautor, partícipe del ilícito. Esta información debe contribuir a descubrir la estructura organizacional, su forma de actuar, los planes que tengan o hayan ejecutado y quienes son los integrantes de la organización. Además, en que lugar se encuentran los efectos, ganancias o bienes obtenidos en la actividad delictiva. Tiene también por finalidad capturar a quienes integran la organización criminal y desactivarlos por completo.

La colaboración eficaz no es una institución nueva: nació en la época romana en función de la recompensa, y fue en Italia en donde tuvo un desarrollo legislativo como normatividad de emergencia frente al nacimiento, evolución y crecimiento de las diferentes organizaciones mafiosas. Por su parte, el derecho penal premial agrupa normas de atenuación o remisión total de la pena, orientadas a premiar y fomentar conductas de desistimiento y arrepentimiento eficaz de la actividad criminal o bien de abandono futuro de dichas actividades delictivas y colaboración con las autoridades a cargo de la persecución penal o en el descubrimiento de los delitos ya cometidos o, en su caso, el desmantelamiento de la organización criminal a la que pertenece el imputado.

Estos beneficios penales son ad optados por los diversos ordenamientosjurídicos por cuestión de pragmatismo, en vista que, los Estados han evidenciado que sus órganos de administración de justicia a través del proceso judicial no son capaces de conocer y resolver efectivamente todos los conflictos penales que se suscitan en la sociedad, siendo concientes políticamente de las carencias que afronta su sistema penal.

Estas disposiciones premiales las encontramos a nivel sustantivo (Derecho Penal - Parte General y Especial), adjetivo (Derecho Procesal Penal) e, incluso, en algunas disposiciones del Derecho Penitenciario. El derecho penal premial descansa en la figura del arrepentido ${ }^{1}$. Se exige que el colaborador mire el futuro orientando al cambio de conducta, es decir a un comportamiento "post patratum delictum". El arrepentido reconoce ante la autoridad los hechos 
delictivos en la cual ha participado y proporciona información suficiente y eficaz, de un lado, para influir sobre la situación antijurídica producida por el delito en sus consecuencias nocivas o peligrosas, o bien, sobre los eventuales desarrollos sucesivos del delito ya realizado; y de otro, para ayudar a la autoridad a buscar pruebas para una eficaz prevención y adecuada represión del delito. Es sobre este tipo de actitud que el derecho penal premial otorga un premio a comportamientos que pueden definirse genéricamente como de "ayuda" o "colaboración " con la autoridad judicial, fiscal o policial, empero ésta información entregada tiene que ser de naturaleza significante y debidamente comprobada.

La doctrina nos enseña que en el procedimiento de colaboración eficaz son cinco los elementos que caracterizan al arrepentido: a) revista la calidad del imputado de un delito vinculado a una organización criminal; b) debe entregar información completa no parcial; c) debe tratarse de una información significante d) esa información tiene una finalidad de identificación de personas o de secuestro de cosas y e) él se favorecerá con una reducción o exención de pena.

En cuanto al concepto de crimen organizado, resulta complicado esbozar una definición conceptual de éste tanto por la heterogeneidad con la que se manifiesta, como por la multitud de sectores sociales y económicos a los que afecta. Sin embargo, su lucha justifica el empleo de medios extraordinarios, tanto del derecho penal como procesal -la colaboración eficaz, el principio de oportunidad, la terminación anticipada, las medidas alternativas a la pena privativa de la libertad, etc.- que quiebran la aplicación de algunos de los principios propios del Estado de Derecho.

La criminalidad utiliza un modelo organizativo, análogo a otros existentes dentro de la estructura social a efecto de cometer la infracción penal e incluso, su escala delictual trasciende ámbitos nacionales. La criminalidad organizada es un fenómeno sociológico que se ha venido incrementando significativamente de manera paralela al propio desarrollo de la sociedad pos-industrial, que genera graves riesgos para la vida social y para el propio Estado de Derecho, y cuyo interés dogmático se extiende a distintos espacios del sistema penal. Por su gran heterogeneidad de grupos criminales organizados, ésta puede clasificarse en: de naturaleza mafiosa (incluye a la criminalidad de cuello blanco); terroristas o subversi vos y de del incuencia común. Es cierto que cada uno de estos tipos de criminalidad reúne caracteres distintos, pero todos ellos ofrecen una complejidad organizativa que dificulta enormemente la persecución de los delitos que cometen. 


\section{LA COLABORACION EFICAZ EN EL PERU: ANÁLISIS CRÍTICO}

En el Perú retomó su vigencia y notoriedad jurídica la institución procesal de la colaboración eficaz como consecuencia de la difusión e incidencia criminosa de los procesos judiciales por corrupción pública generados en el gobierno del procesado Alberto Fujimori, empero, es pertinente expresar que ésta ya tenía vigencia desde la dación del Decreto Ley $\mathrm{N}^{\circ} 25499$ y luego, sus modificaciones con las Leyes $\mathrm{N}^{\mathrm{o}} 26220,26345,27378,27765,28008$, y 28950. También regulan su aplicación los Decretos Legislativos 925 y 987. En síntesis, no es novedad en el Código Procesal de 2004 lo que sucede es que anteriormente solo estaba circunscrito su ámbito de aplicación a los delitos de terrorismo en sus diferentes modalidades (Ley $\mathrm{N}^{\mathrm{O}} 25475$ ), hoy es uno de los siete procesos especiales ${ }^{2}$, cuya tramitación es totalmente diferente a la estructura del proceso penal común que prevé el Código Procesal de 2004.

El Código Procesal Penal del año 2004 autoriza al Ministerio Público a celebrar un acuerdo de beneficios y colaboración con una persona imputada, procesada o responsable de un delito, si se verifica que la información que entrega a la Policía o al Fiscal es cierta, comprobable, y tiene consistencia probatoria; al respecto, el artículo $472^{\circ}$ del citado cuerpo normativo exige concurrentemente en su inciso segundo que el informante haya abandonado voluntariamente sus actividades delictivas; me parece que en este extremo la ley procesal exagera cuando exige que el informante debe "haber abandonado voluntariamente sus actividades delictivas" está disposición contiene una construcción lingüística que no permite que se acojan a este beneficio sujetos que hayan cometido sucesivos ilícitos o estén por cometerlos, es decir no podrán ser calificados como beneficiarios para entregar información de un hecho criminal anterior donde intervino como autor o partícipe, si es que no dejaron definitivamente el delito, me pregunto ¿el Código Procesal puede poner límites a un sujeto o reglar la conducta a futuro de un individuo? La respuesta es no; quiero entender que lo que busca dicho precepto es cumplir una doble función, por un lado, exigir como requisito que el futuro informante abandone sus actividades ilícitas y por otro, cumpla el rol de prevención general; sería estratégico $^{3}$ que se reconduzca legislativamente dicho requisito "al sujeto que se desista, que haya exteriorizado todas las acciones ejecutivas del ilícito o que permita evitar resultados típicos en el futuro" o en otras palabras "el abandono del hecho o acción criminal en toda su extensión que es materia de imputación penal y pueda ser pasible de colaboración eficaz" porqué exigirle haber abandonado definitivamente sus actividades ilícitas, sabemos que eso es irreal, por lo general el delincuente nace, crece en el tiempo con el crimen, muere también con él; estimo que lo que realmente interesa al país y al sistema 
penal por estrategia política criminal y procesal es que no haya impunidad, se conozca o desbarate las organizaciones criminales o se encuentren sus efectos o ganancias ilícitas.

Por otro lado, si bien es cierto, esta institución procesal ha ampliado su ámbito de aplicación de su primigenia ley a los delitos de a) asociación ilícita, terrorismo, lavado de activos, contra la humanidad; b) secuestro agravado, robo agravado, abigeato agravado, así como delitos monetarios y tráfico ilícito de drogas, siempre que en todos estos casos el agente actúe en calidad de integrante de una organización delictiva y c) concusión, peculado, corrupción de funcionarios, tributarios, aduaneros, contra la fe pública y contra el orden migratorio, siempre que el delito sea cometido en concierto por una pluralidad de personas; pero también lo es, que ha omitido figuras penales que tienen alta incidencia en la criminalidad ordinaria como violación sexual en agravio de menores de edad, homicidio calificado, pornografía infantil, trata de blancas, tráfico de personas, robo de vehículos a través de bandas criminales, etc.; al respecto, pienso que debe ampliarse en el futuro. Este beneficio debe admitirse para cualquier ilícito, porqué hacer distinciones.

Asimismo, no comparto la disposición legal cuando dice que sólo pueden acogersea la colaboración eficaz aquél sujeto que ha intervenido necesariamente en el delito a descubrirse o delatarse, es decir no le es aplicable este beneficio a aquella persona que no ha intervenido como cómplice ni actúo en calidad de integrante de una organización criminal ni ha sido cometido por pluralidad de sujetos en hecho criminal ajeno; considero que el legislador ha partido de la tesis que solamente pueden ser sujetos o beneficiados del acuerdo por colaboración eficaz aquellas personas que han intervenido en calidad de autores o partícipes del mismo hecho punible a descubrirse o delatarse o a entregar información, pienso que esta posición legislativa es restrictiva por las siguientes razones: a) que pasaría si " $x$ " persona es un delincuente avezado que ha participado en incontables crímenes impunes, pero determinado día es testigo presencial de un delito de violación sexual de una menor de edad o de un homicidio que ha sido ejecutado por una persona no descubierta por nadie, sin embargo " $x$ " lo conoce $y$ sabe dónde domicilia o ubicarlo; pregunto acaso no es razonable y es acorde a nuestra realidad social recibir la información de " $x$ " que no participó en el evento delictivo a cambio que él reciba beneficios por colaboración eficaz (reducción o disminución de la pena a recibir, medidas alternativas a la pena privativa de la libertad, liberación condicional, etc.), de su delito o de los otros sujetos intervinientes.

En esa línea del Código como no es su hecho del colaborador o el ilícito penal ha sido cometido por un solo sujeto activo no es procedente aceptarle que se 
acoja a los beneficios de la colaboración eficaz. b) en otra hipótesis porqué no es aplicable los beneficios de la colaboración eficaz al interno sentenciado que cumple condena efectiva o al procesado que no tiene la condición de cabecilla ni líder de la organización criminal, pero conoce y quiere entregar información veraz y significante de cómo funciona la mafia dentro del establecimiento penitenciario respecto a la corrupción de funcionarios, comercialización de drogas, cobros ilegales, fabricación de alcohol con productos artesanales, prostitución, ingreso de celulares y armas de fuego, etc., a cambio de la disminución de su pena impuesta o liberación condicional, etc. y medidas de protección para él y su familia.

No aceptar o reconocer esta situación fáctica por el legislador dentro del procedimiento de la colaboración eficaz es simplemente dejar que las mafias se enquisten, crezcan, desarrollen, genere y se perciba impunidad. No aceptar lo que realmente sucede en nuestra realidad social jurídica es vivir apartado del problema real y no tener en cuenta la problemática al momento de legislar y ello, tiene una respuesta clara, al momento de legislar o asesorar simplemente aceptan leyes importadas o posiciones doctrinales ajenas a la realidad del Perú, es válido nutrirse de teorías de otras latitudes, pero también lo es, que estas deben responder o adecuarse a los hechos reales del país. c) lo que busca finalmente la colaboración es la lucha eficaz contra el delito en sus diferentes clases de criminalidad, entonces, si ese es su objeto porque no ponerse en todas las probables situaciones que se presentan en la realidad social. La colaboración no solo es una medida de corte político criminal sino también una estrategia procesal para enfrentar a la impunidad delictiva o el descubrimiento de las organizaciones criminales que descansa sus bases en el derecho penal premial, éste no delimita el ámbito de aplicación o a quienes se les debe aplicar, tampoco dice que la información a entregarse por el probable beneficiario debe ser de su propio hecho criminal, lo que le interesa al derecho premial es compensar mediante reglas de atenuación o de remisión de la pena o beneficios a favor del arrepentido, entonces, la manera como se ha legislado es responsabilidad del codificador, no por que lo imponga el derecho penal premial.

Bajo la premisa expuesta para nosotros el desarrollo doctrinal de los alcances de este instituto procesal (la colaboración) en nuestro país debe ser construido mirando lo que sucede internamente en la realidad nacional y no, lo que se importa del exterior $u$ otras realidades jurídicas. d) por otro lado, si la voluntad del Estado apunta a reducir carga procesal o beneficiar con medidas de protección o dar incentivos punitivos o penitenciarios a aquellos sujetos que están dispuestos a reconocer su culpabilidad y delatar a los demás integrantes de la organiza- 
ción o entregar información significante sobre su ubicación o sobre los efectos del delito cometido en la investigación preliminar o en las diversas etapas del proceso penal común en el Código Procesal Penal de 2004 (investigación preparatoria, intermedia o juzgamiento) a fin de descubrir a los autores o partícipes desconocidos o no habidos del delito, etc., creo que no se debe condicionar a que el futuro colaborador haya cometido el crimen en calidad de integrante de una organización criminal o por una pluralidad de sujetos, porque no respondería a una estrategia sostenida y con objetivos reales.

Estimo por el contrario, si la ley procesal reconduce su alcance y permite que no solamente sean sujetos merecedores de la colaboración eficaz personas que no participaron en el hecho punible, pero tienen conocimiento de un hecho criminal y saben quien es el autor o autores, la cuestión sería diferente porque estaríamos coincidiendo con lo que realmente es la esencia de la colaboración eficaz. Por ejemplo, si es aceptada esta propuesta podrían ser calificados como informante o colaborador aquél sujeto que ha sido judicialmente declarado responsable de un delito y merecedor de una sanción penal, por citar otra hipótesis un recluso está condenado a 20 años de pena privativa de la libertad y decide brindar información válida y verificable sobre las redes del crimen organizado en cualquiera de sus figuras penales previstas concusión, peculado, corrupción de funcionarios, tributarios, aduaneros, contra la fe pública y contra el orden migratorio, etc., donde él no ha participado como autor o partícipe, pero que ha logrado tener conocimiento, pregunto ¿si nos ceñimos a lo que quiere la ley procesal sería posible aceptarlo como beneficiario de la colaboración? la respuesta es negativa ¿qué impedimento habría? sólo la disposición legal cuando dispone “...siempre que el delito sea cometido en concierto por una pluralidad de personas..." estoy plenamente convencido que el titular de la acción penal al conocer la información, va explotarla al máximo y esto contribuiría a lograr la eficacia de la colaboración eficaz y a reducir impunidad. e) ¿qué pasaría si un recluso condenado decide contar con lujos y detalles la forma en que actúan los cabecillas o lideres de una organización que se dedican a planificar o negociar desde su celda con los familiares o amigos de un secuestrado a fin de obtener el provecho económico? me pregunto ¿acaso no es posible bonificarle algunos rangos en la disminución de su pena o la aplicación de los beneficios que ha previsto el artículo $474^{\circ}$ inciso 2) a una persona rematada a cambio de una información válida y cierta? resulta ilógico no aceptar ser beneficiario de la colaboración y contradictorio con los fines que persigue esta institución procesal.

Por otra parte, para que una persona sea calificada como beneficiario de colaboración eficaz deberá entregar información válida que logre: evitar la eje- 
cución y consumación de un delito, o las consecuencias post delito; impedir o neutralizar futuras acciones delictivas; conocer la forma y circunstancias de la consumación del delito o la que se encontrare en grado tentativa; identificar a los autores y partícipes involucrados en la acción criminal, además la estructura piramidal de la organización criminal que permita desarticular o detener a uno o varios de sus miembros; recoger e incautar los instrumentos, efectos, ganancias y bienes provenientes del acto delincuencial; asimismo, averiguar la ubicación o destino de ellos, o indicar las fuentes de financiamiento y aprovisionamiento de la organización delictiva; se debe reconocer que la ley procesal en cuanto a los requisitos de validez de la información es de avanzada, ya que no solamente quiere conocer sobre el hecho punible, si no además todo aquello que esté estrechamente vinculado autores, cómplices, modus delictivo, ramificaciones, contactos, medios empleados, ubicación de los sujetos responsables, destino de los objetos, etc., sin embargo, su optimización está supeditada a que el órgano o institución que se va encargar de la investigación y verificación de la información trabaje con reserva, calidad, eficacia y celeridad, por citar, si no crean y centralizan una base de datos con todas las variables citadas en la ley no estarán en condiciones en el futuro de poder atender las demandas de colaboradores y brindar en el futuro una proyección sostenida para las políticas criminales en el país. Si la información resultare falsa o no comprobada en las diligencias de verificación de la Policía o del Ministerio Público, éste tiene la facultad de denegar la solicitud al beneficio de colaborador, no siendo impugnable su decisión.

Debe reconocerse que el Código Procesal de 2004 ha previsto que si en la investigación o proceso penal por colaboración eficaz se presente un concurso de acciones típicas, donde uno de los ilícitos aparezca previsto en el artículo $473^{\circ}$ y el otro no, ello no resta ni excluye la posibilidad que en muchas investigaciones se presenten figuras penales que no aparezcan previstas en la ley pero como se trata de un concurso de delitos (ideal o real) si es posible acceder a los beneficios de colaboración. Pienso que al no consignar el Código a algunas otras figuras penales lo hace con la finalidad de solo incluir dentro de la colaboración a los ilícitos que tenga que ver con el crimen organizado, si ese es su razonamiento entonces debe incluir a los delitos que hemos citado líneas arriba porque su perpetración requiere de una organización delictiva.

Entre las características de la colaboración eficaz podemos citar que el Ministerio Público y la Policía son los encargados de verificar y comprobar la información entregada por el colaborador, persigue el aceleramiento y eficacia de la justicia penal, los cargos que no acepte el informante, no formarán parte del acuerdo de beneficios, está restringido a determinados 
agentes del delito. No se podrán acoger a ningún beneficio premial los jefes, cabecillas o dirigentes principales de la organización delictiva, el acuerdo de beneficios está sujeto a la aprobación judicial, si es denegado el beneficio (por el Fiscal o Juez) las diversas declaraciones formuladas por el colaborador se tendrán como inexistentes y no podrán ser usados en su contra. Las versiones entregadas por terceros durante la etapa de verificación de la información, así como la prueba documental, los informes o dictámenes periciales y diligencias irreproducibles mantendrán su validez y podrán ser valoradas en otros procesos penales.

Los beneficios premiales después de la verificación de la información están en función del grado de eficacia o importancia de la colaboración, ellos son a) exención de la pena; b) disminución de la pena hasta un medio por debajo del minimum legal; c) suspensión de la ejecución de la pena; d) liberación condicional y e) remisión de la pena para quien la esté cumpliendo. En la disminución de la pena se puede aplicar acumulativamente con la pena condicional (siempre que concurran los requisitos del artículo $57^{\circ}$ del Código Penal). Al colaborador se le puede variar el mandato de detención por comparecencia con restricciones (artículo $288^{\circ}$ del Código Procesal Penal y $143^{\circ}$ del Código adjetivo actual) e incluso, por el de detención domiciliaria. En cuanto al beneficio de la reducción de la pena puede reducirse hasta por un sexto $(1 / 6)$ el mismo que es adicional y acumulable a la bonificación de la confesión sincera. También podría beneficiarse con la liberación condicional siempre que haya cumplido como mínimo la mitad de la pena impuesta. Si consiste en la disminución de la pena, declarará la responsabilidad penal del colaborador y le impondrá la sanción que corresponda según los términos del acuerdo, sin perjuicio de imponer las obligaciones pertinentes. Si el acuerdo aprobado consiste en la exención o remisión de la pena, así lo declarará, ordenará su inmediata libertad y la anulación de los antecedentes del beneficiado.

Para la aplicación de los beneficios de la exención de pena y remisión de la pena obligatoriamente la información debe permitir: a) evitar la comisión de un delito de especial connotación y de suma gravedad; b) identificar y propiciar la detención de lideres de especial importancia en la organización delictiva; c) descubrir fehacientemente aspectos de las fuentes de financiamiento y aprovisionamiento de la organización delictiva y d) descubrir fehacientemente los bienes, efectos y ganancias de notoria importancia de la organización delictiva. Insisto acaso los delitos de violación sexual en agravio de menor de edad no son graves, si, la diferencia está en la naturaleza del delito que muy pocas veces lo cometen una pluralidad de sujetos activos. 
Si el fiscal luego de verificar la información entregada por el beneficiario estima que la información entregada es significante o eficaz elaborará un acta de beneficios con el beneficiario en el que constará: a) el beneficio acordado; $b$ ) las obligaciones a las que queda obligado y c) los hechos a los cuales se refiere el beneficio y la confesión en caso se produjere. Y si el fiscal estimara que la información entregada no es veraz, denegará la celebración del acuerdo; en este caso, ordenará se proceda contra el solicitante conforme al resultado de las investigaciones. En ambos casos la decisión del fiscal no es impugnable. Si el juez considera que el acuerdo no adolece de infracciones legales, no resulta manifiestamente irrazonable, o no es evidente su falta de eficacia, lo aprobará e impondrá las obligaciones que correspondan. La sentencia de conformidad no podrá exceder los términos del Acuerdo.

Si la investigación de la información entregada por el solicitante arrojara indicios suficientes de la participación de las personas señaladas, el fiscal procederá a decidir el inicio de la prosecución penal. Si la persona señalada por el colaborador fuera declarado inocente por la justicia es procedente la entrega de su identificación (del colaborador) a efectos que proceda en defensa de sus derechos o fines legales que decida.

Cuando la entrega de información eficaz se refiera a hechos que se encuentren en otras etapas del proceso penal si es antes del juicio oral el fiscal remite el acta de acuerdo de beneficios y colaboración al juez, el mismo que celebrará una audiencia privada especial para aprobar o desaprobarlo. La decisión del juez es apelable. Si la entrega de la información eficaz es después de haberse emitido la sentencia el Juez de la investigación preparatoria convoca a audiencia privada a efectos de aprobar o desaprobar el acuerdo, en caso, lo apruebe podrá conceder remisión de la pena, suspensión de la ejecución de la pena, liberación condicional, conversión de pena privativa de la libertad por multa, prestación de servicios o limitación de días libres conforme equivalencias del artículo $52^{\circ}$ del Código Penal. En este caso, si el juez rechaza el acuerdo deberá motivar su decisión, el mismo que es apelable.

El beneficiado con la colaboración tiene condiciones, obligaciones y control; la concesión del beneficio está condicionada a que el favorecido no cometa nuevo delito doloso dentro de los 10 años de habérsele otorgado. Además el Juez debe imponerle una o varias obligaciones (reglas de conducta artículo $479^{\circ}$ Código Procesal Penal). Las obligaciones estarán en función de la naturaleza y modalidades del hecho punible perpetrado, las circunstancias de tiempo, modo y lugar en que se cometió, la naturaleza del beneficio y la magnitud de la colaboración proporcionada, así como de sus condiciones personales. 
Es factible que el beneficiado garantice sus obligaciones mediante caución o fianza, si las posibilidades económicas del colaborador lo permiten. El control de las obligaciones le corresponde al Ministerio Público.

En cuanto al procedimiento de revocatoria de los beneficios de la colaboración eficaz: el fiscal con la investigación efectuada podrá solicitar al juez que otorgó el beneficio premial la revocatoria del mismo. Se corre traslado por el término de 05 días, luego, efectuará la audiencia de revocatoria de beneficios con asistencia obligatoria del fiscal. Si no asiste el beneficiado, continua la audiencia, en ese caso se le designa un abogado de oficio. Escuchará a las partes y luego en un plazo no mayor de 03 días emite la resolución respectiva. Esta resolución es apelable. Si la revocatoria es sobre la exención de pena: se remite los actuados al fiscal para que formule acusación y pida la pena que corresponda. El juez inmediatamente en audiencia pública dictará el auto de enjuiciamiento, corre traslado a las partes por 05 días para que aleguen lo que crean pertinente, formulen pretensiones y ofrezcan las pruebas pertinentes para la sanción y reparación civil, vencido el plazo se lleva a cabo el juzgamiento respectivo. Si la revocatoria se refiere a la disminución de la pena: se remite los actuados al fiscal para que formule la pretensión de condena correspondiente. El juez inmediatamente celebrará audiencia pública con citación de las partes y conocimiento del requerimiento fiscal a fin que en el plazo de 05 días aleguen lo pertinente y ofrezcan las pruebas. Después se lleva a cabo la audiencia con examen, actuación de pruebas y alegatos orales. Si la revocatoria se refiere a remisión de la pena: el juez que dicta la revocatoria del beneficiado debe ordenar que el imputado cumpla el extremo de la pena remitida. Si la revocatoria se refiere a la suspensión de la ejecución de la pena, liberación condicional, detención domiciliaria o comparecencia: se regirá en lo pertinente por las normas penales, procesales o de ejecución penal. En todos lo casos para proceder a llevarse a cabo la audiencia respectiva la resolución que revoca debe tener la condición de firme y/o ejecutoriada.

Las medidas de protección están dirigidas a favor del colaborador, testigos, peritos y agraviados que brinden colaboración eficaz y exista un peligro grave para la persona, libertad o bienes. Así como para sus ascendientes y descendientes. Las medidas buscan preservar la identidad del protegido, su domicilio, profesión y lugar de trabajo y ellas son: a) protección policial; b) cambio de residencia; c) ocultación de paradero; d) reserva de su identidad en las actuaciones procesales, pudiendo utilizarse un número o clave; e) utilización de cualquier procedimiento que imposibilite su identificación visual normal y f) fijación como domicilios para efecto de las citaciones la sede de la Fiscalía, debiendo notificarse en forma reservada por ella a los 
protegidos. Tratándose de funcionarios o servidores públicos y magistrados deberán adoptarse medidas de protección respecto a los derechos laborales.

\section{PROPUESTAS}

1. Que nuestro sistema procesal penal extienda el ámbito de aplicación del colaborador eficaz para toda aquella persona investigada, procesada $o$ sentenciada que conozca información significante sobre la planificación o ejecución de actividades delictivas que pertenezcan al crimen organizado, sin necesidad que el informante haya participado como autor o partícipe en los hechos que brindará información. No deben aplicarse los beneficios solo a aquellos que informen de su hecho criminal, sino por el contrario, de cualquier hecho criminal grave que tuvieran un conocimiento veraz y cierto.

2. Que se incorpore como beneficio del colaborador sentenciado a la figura de la reducción de la condena por escalas de un tercio o un sexto o un medio de la pena impuesta a efecto que el Juez que emitió la condena pueda tener mayores elementos valorativos según la naturaleza o magnitud de la información aprobada. Esta propuesta también tiene por objeto ir despoblando progresivamente las cárceles del país.

3. Que el Congreso de la República expida una ley que disponga la vigencia en todo el país no solamente la sección de la colaboración eficaz (artículos $472^{\circ}$ al $481^{\circ}$ ) sino todo el capítulo de los procesos especiales que aparecen en el Código Procesal de 2004 (artículos $446^{\circ}$ al $487^{\circ}$ ) con excepción de la terminación anticipada que está vigente.

4. Que el Ministerio Público inicie una campaña de difusión respecto a las bondades y beneficios que genera acogerse a la colaboración eficaz a efecto de reducir y/o minimizar la impunidad delictiva.

5. Que el Congreso de la República o la autoridad estatal respectiva aprueben el proyecto de reglamento respecto a los procedimientos a seguir respecto a beneficios, colaboración y medidas de protección conforme al Proyecto elaborado por la Comisión de alto nivel del año $2005^{4}$.

6. Debe crearse una Unidad policial adscrita a la Fiscalía de la Nación a efecto de dar protección a los Beneficiados o Testigos o Peritos o agraviados que brinden información en el procedimiento de colaboración eficaz. 
7. Que se construyan ambientes especiales dentro de los establecimientos penitenciarios del país a efecto que sean internados aquellos beneficiados con otro código de identidad o en todo caso, los que utiliza actualmente la Policía deben ser custodiados en forma conjunta con el INPE.

8. Debe ampliarse los delitos que pueden ser objeto de acuerdo por colaboración eficaz conforme a lo expuesto en este artículo.

9. Debe existir un registro único de colaboradores en el Poder Judicial, el Ministerio Público y la Policía a fin de centralizar y explotar adecuadamente dicha información en la lucha contra el crimen.

1 Se refiere a aquel sujeto activo cualquiera fuera su rol en la comisión de un delito no descubierto por la justicia. Éste arrepentido se siente perseguido por su conciencia o por la Policía o también asume la postura de colaborar en el esclarecimiento del delito por estrategia procesal. No debe confundirse con la figura del arrepentimiento activo que tiene por objeto evitar el resultado típico de una conducta totalmente desplegada en el mundo externo o con el desistimiento que asume el sujeto con la finalidad de continuar los actos de ejecución criminal.

2 Los procesos especiales son: 1) el proceso inmediato, 2) el proceso por razón de la función pública (atribuidos a los altos funcionarios públicos, atribuidos a congresistas de la república y a otros altos funcionarios públicos y por delitos de función atribuidos a otros funcionarios públicos), 3) el proceso de seguridad, 4) por ejercicio privado de la acción penal, 5) por terminación anticipada, 6) por colaboración eficaz y 7) el proceso por faltas.

3 Con la finalidad de lograr que más sujetos activos del delito se acojan a la colaboración eficaz; sabemos por experiencia profesional que muchas personas que viven al margen de la ley, han delinquido, delinquen o probablemente lo sigan haciendo, el delito nunca va a desaparecer, la personalidad delincuencial tampoco lo será de la noche a la mañana. Considero que es estratégico modificar la legislación procesal a favor de la eficacia contra el delito que la mayor cantidad de arrepentidos colaboren, no se les debe limitar a ser postulantes a entregar información de organizaciones criminales, si se les debe obligar a no cometer nuevo delito doloso en el futuro, empero después de haberse aprobado su convenio de beneficios, antes me parece un obstáculo procesal.

4 Tuvimos el honor de participar en dicha Comisión como representante del Señor ex Presidente del Poder Judicial, en ella se trabajo un Proyecto de Ley y un Proyecto de Reglamento que está en el Congreso de la República y el Ministerio de Justicia para su aprobación. Compartimos esta comisión con el destacado procesalista, hoy Fiscal Supremo Dr. Pablo Sanchez Velarde. 